\title{
Excessive Daytime Sleepiness, Sleep Hygiene, and Work Hours Among Medical Residents in India
}

\author{
David F. Mastin, ${ }^{1}$ H. S. Siddalingaiah, ${ }^{2}$ Amarjeet Singh, ${ }^{2}$ and Vivek Lal ${ }^{2}$ \\ ${ }^{1}$ University of Arkansas at Little Rock, USA \\ ${ }^{2}$ Postgraduate Institute of Medical Education and Research (PGIMER), Chandigarh, India
}

\begin{abstract}
The purpose of this study was to examine the relationship between sleep hygiene, excessive daytime sleepiness and work hours among resident physicians in Chandigarh, India. Data were collected from 350 volunteering junior resident doctors and included sociodemographic variables, excessive daytime sleepiness (EDS) as measured by the Epworth Sleepiness Scale (ESS), sleep hygiene as measured by the Sleep Hygiene Index and hours worked. Almost half of the resident physicians studied reported a problem of EDS and maladaptive sleep hygiene practices. Physicians working more than 80 hours per week and physicians with more maladaptive sleep behaviours were much more likely to report EDS. The authors propose that sleep hygiene and number of hours slept should be considered as EDS prevention and treatment strategies, especially for physicians working less than 80 hours per week. The authors also propose that the most salient intervention for physicians working more than 80 hours per week is one of workplace advocacy, where the government is encouraged to adopt legally binding guidelines as seen in other countries.
\end{abstract}

- Keywords: Excessive Daytime Sleepiness, Epworth Sleepiness Scale, Sleep Hygiene Index, Sleep Quality, Sleepiness, Sleep Hygiene, Sleep Deprivation

Sleep disturbances have become quite common for the general public in modern society due to factors such as increased pace, stressful lifestyles and increased travel (Souza, Magna, \& Reimao, 2002; Tsuno et al., 2007; Zielinski, Polakowska, Kurjata, Kupsc, \& Zgierska, 1998). Sleep disorders are encountered in all age groups, all societies and segments of society (Joo et al., 2005; Kaneita et al., 2005; Liu, Uchiyama, Kim et al., 2000; Liu, Uchiyama, Okawa, \& Kurita, 2000; Ohayon \& Lemoine, 2004; Ohida et al., 2004). The prevalence of excessive daytime sleepiness (EDS) varies in different settings from 2 to $37 \%$ in the general population to 7 to $84 \%$ in working populations such as resident doctors, nurses, shift workers, business process outsourcing (BPO) employees and internet technology (IT) professionals (Doi, Minowa, \& Futija, 2002; Hanlon, Hayter, Bould, Joo, \& Naik, 2009; Howard, Gaba, Rosekind, \& Zarcone, 2002; Mello et al., 2000; Suzuki, Ohida, Kaneita, Yokoyama, \& Uchiyama 2005).

There are some segments of society where problems related to sleep primarily result from external factors, such as night-shift work, and may have a substantial impact on the productiveness of their work (Akerstedt, 2003; Defoe, Power, Holzman, Carpentieri, \& Schulkin, 2001; Saxena \& George, 2005). The medical profession is not untouched by this malady, particularly in the case of resident doctors and nursing staff (Suzuki et al., 2005; Veasey, Rosen, Barzansky, Rosen, \& Owens, 2002).

Long work hours are a time-honoured tradition in most residency programs in hospitals. Demanding schedules are often said to be necessary for learning and development of professionalism among doctors (Wols, Kramer, \& Strange, 1995). The use of resident physicians to provide relatively inexpensive coverage has also become an important economical factor for teaching hospitals all over the world. In such a scenario, disturbed sleep has become an accepted norm of residency training (Defoe et al., 2001; Gander,

ADDRESS FOR CORRESPONDENCE: David F. Mastin, Department of Psychology, University of Arkansas at Little Rock, 2801 South University Avenue, Little Rock, Arkansas.

E-mail:dfmastin@ualr.edu 
Purnell, Garden, \& Woodward, 2007; Howard et al., 2002). However, consequences of sleep problems in medical and nursing professions can have serious repercussions because of the life-saving responsibilities of these individuals (Gaba \& Howard, 2002; Papp et al., 2004; Veasey et al., 2002).

Sleepiness is commonplace among hospital staff. For example, more than $10 \%$ of resident doctors perceive sleepiness as an almost daily occurrence for themselves (Rosen, Bellini, \& Shea, 2004). This raises concerns about whether increased sleepiness and fatigue impair the cognitive and performance skills of resident doctors (Krueger, 1994; Papp et al., 2004). The effects of EDS on daytime functioning, cognition, memory, accidents and work errors is well studied in some countries such as the United States (US), Australia, Japan and France (Bartel, Offermeier, Smith, \& Becker, 2004; Roth \& Roehrs, 1996, 2003; Suzuki et al., 2005; Van Cauter et al., 2007; Webb, 1995). However, similar studies on sleep are lacking in the Indian population.

Research in the US has shown a steady decline in the time adults spend asleep, accompanied by an estimated yearly cost to society of sleep problems ranging in the tens of billions of US dollars.(Daley, Morin, LeBlanc, Gregoire, \& Savard, 2009; Leger, 1994; Webb, 1995) This is creating an interest in improving sleep quality as well as sleep habits, which have been shown to improve sleep quality (Daley, Morin, LeBlanc, Gregoire, \& Savard, 2009; Daley, Morin, LeBlanc, Gregoire, Savard, et al., 2009; Jennum, Knudsen, \& Kjellberg, 2009; Kleinman, Brook, Doan, Melkonian, \& Baran, 2009; Leger, 1994; Presser, 1999; Vauth \& Greiner, 2009; Webb, 1995).

Sleep hygiene has been defined as practising behaviours that facilitate sleep and avoiding behaviours that interfere with sleep (Brown, Buboltz, \& Soper, 2002; Mindell, Meltzer, Carskadon, \& Chervin, 2009). They are simple behaviours that can be undertaken at little to no extra cost by simple lifestyle modifications. Most are thought to influence good functioning and performance by ensuring better quality restorative sleep.

Sleep hygiene has recently been made quantifiable by the development of valid scales such as the Sleep Hygiene Index (SHI; Mastin, Bryson, \& Corwyn, 2006) and has been linked to EDS. The purpose of this study is to examine the doseresponse association between sleep hygiene and EDS using available quality measuring instruments like SHI and the Epworth Sleepiness Scale (ESS; Johns, 1991). There are no studies that have examined sleep hygiene and sleepiness in India.

Regardless of nation, the literature available on quantification of sleep hygiene is scant and, given the importance of good sleep quality and quantity on short- and long-term health of individuals, this should be studied and understood scientifically. Understanding the relationship between sleep hygiene and sleepiness will widen the avenue into the therapy of sleep problems regardless of etiology. Recent literature suggests the role of nonpharmacological therapies is important in treating many sleep problems (Azad, Byszewski,

\section{TABLE 1}

Socio Demographic and Lifestyle Profile of Study Participants

\begin{tabular}{llrr}
\hline Socio-demographic factor & Categories & Frequency & Percent \\
\hline Sex & Men & 282 & 80.6 \\
& Women & 68 & 19.4 \\
\hline Marital status & Married & 92 & 26.3 \\
& Not married & 258 & 73.7 \\
\hline Coffee-tea (cups/day) & No & 194 & 55.4 \\
& 1-2cups & 229 & 65.4 \\
& $>$ ccups & 120 & 34.3 \\
\hline Smoking & Yes & 28 & 8.0 \\
& No & 321 & 91.7 \\
\hline Physical activity frequency in & None & 212 & 60.7 \\
addition to work in a & 1-3 days a week & 107 & 30.7 \\
week & $>4$ days a week & 30 & 8.6 \\
\hline Physical activity duration in & $<30$ min & 241 & 69.3 \\
addition to work in a & 30 min to 2 hours & 81 & 23.3 \\
week & $>2$ hours & 26 & 7.5 \\
\hline BMl & Low & 18 & 5.1 \\
& Normal & 234 & 66.9 \\
& Obese & 87 & 24.9 \\
\hline
\end{tabular}

Prevalence of Sleepiness and Poor Sleep Hygiene

Sarazin, McLean, \& Koziarz, 2003; Chesson et al., 1999; Harsora \& Kessmann, 2009; Hoch et al., 2001; Siriwardena et al., 2009; Stepanski \& Wyatt, 2003; Weiss, Wasdell, Bomben, Rea, \& Freeman, 2006; Wildschiodtz \& Rasmussen, 1981). Further, clarifying the sleep hygienesleepiness relationship should be particularly useful in population groups where hours are long and/or unpredictable, such as resident doctors, shift work employees, IT and BPO professionals.

\section{Method}

\section{Participants}

Data were solicited from 430 volunteering junior resident doctors $(M=26.6$ years, $S D=2.2$ years; $80.6 \%$ male, $16.4 \%$ female) from an urban teaching hospital in India over the course of 12 months. The sociodemographic factors (refer to Table 1) showed $80.6 \%$ of the participants were male and $19.4 \%$ were female. The age range of the respondents was from 21 to 37 years. Among the study participants $26.3 \%$ were married and $73.3 \%$ were unmarried. Of the 430 resident doctors contacted, 2 were excluded and 350 responded. The response rate was $81.77 \%$. The study was approved by a university institutional review board and all participants provided written consent prior to being enrolled in the study.

Of the 350 participants studied in the survey, 303 (86.6\%) belonged to clinical departments and 47 (13.4\%) to nonclinical departments. The clinical participants primarily came from the departments of anaesthesia (10.6\%), medicine $(16.9 \%)$, surgery $(24 \%)$, and paediatrics $(15.7 \%)$. The 
nonclinical participants primarily came from the departments of biochemistry (0.9\%), microbiology (2.9\%), pathology $(1.4 \%)$, pharmacology $(2.9 \%)$, community medicine $(2.6 \%)$ and radio-diagnosis $(2.6 \%)$.

\section{Measures}

Sleep assessment proforma. Information was collected on sociodemographics and sleep-related factors for descriptive purposes (Sandia National Laboratories \& Sandia Corporation, 2007).

Epworth sleepiness scale. The ESS is an 8-item selfadministered questionnaire producing scores that range from 0 (low sleepiness) to 24 (high sleepiness) with scores exceeding 10 indicating abnormal levels of sleepiness (Johns, 1991). The ESS has demonstrated good validity in correlating with objective measures of sleepiness and an ability to discriminate between control subjects and those with significant sleep disorders (Johns, 1991, 1992; Miletin \& Hanly, 2003). Scores were evaluated as 0-9 normal, 10-12 mild EDS, 13-14 moderate EDS, > 14 severe EDS (Zielinski et al., 1998).

Sleep hygiene index. The SHI is a 13-item selfadministered Likert scale index that assesses behavioural patterns associated with sleep hygiene practices. Responses to each item are based on the frequency with which the person engages in the behaviour from 1 (never) to 5 (always). Items are summed to provide a global assessment of sleep hygiene with scores ranging from 13-65. Higher global scores are indicative of more maladaptive sleep hygiene practices (Mastin et al., 2006). For the purposes of this study, a score below 26 was considered good, 27-34 as average, and 35 and above was considered as poor sleep hygiene (Mastin et al., 2006). The internal consistency for the SHI is moderate $(\alpha=0.66)$, and expected for an instrument with independent causal indicators. Mastin and colleagues (2006) demonstrated good test-retest reliability for the SHI $(r=0.71)$. The SHI has been correlated with the PSQI and ESS (Mastin et al., 2006).

\section{Procedure}

All participants completed a package that included a demographics form, SHI, ESS, sleep assessment questionnaire and informed consent. Participants were able to complete the package in less than 50 minutes. All data was stored in a secure location and subjects were assured all responses would remain confidential. Subjects were met in their respective department or place of work and, for those volunteering, appointments were made for data collection. Informed consent and sociodemographic data were collected followed by self-administration of the instruments in sequence of the sleep assessment proforma, ESS and SHI. The data collection was conducted mainly in the afternoons, postlunch sessions and early evening. A significant number of subjects
TABLE 2

Total ESS and SHI Scores

\begin{tabular}{lccccc}
\hline & Normal & Mild & Moderate & Severe & $\begin{array}{c}\text { Total } \\
\text { abnormal } \\
\text { Scale Scores }\end{array}$ \\
$\mathrm{n} \mathrm{( \% )}$ & $\mathrm{n}(\%)$ & $\mathrm{n}(\%)$ & $\mathrm{n}(\%)$ & $\mathrm{n}(\%)$ \\
\hline ESS scores & $183(52.3)$ & $91(26)$ & $33(9.4)$ & $42(12)$ & $166(47.4)$ \\
SHI scores & $50(14.3)$ & $290(83.1)$ & $9(2.6)$ & $299(85.7)$ \\
\hline \multicolumn{7}{l}{ Prevalence of Poor Sleep Quality }
\end{tabular}

(about 70\%) were allowed to return the forms after completing them in their free time. Subjects who were pregnant, sick or admitted as patients to the hospital were excluded from the study.

\section{Results}

\section{Participant Characteristics}

Included in Table 1 are participant characteristics that might be associated with poor health or sleep disruption. For example, the consumption of more than two cups of tea/coffee was reported by $34.3 \%$ of the study participants and $42.3 \%$ of the study participants consumed coffee or tea within four hours of bedtime. Smoking tobacco was reported by $8 \%$ of the study participants. Body mass index (BMI) was found to be normal in $66.9 \%$, obesity range in $24.9 \%$ and lower range in $5.1 \%$ of the study participants. Some behaviours of interest, and potentially associated with health and sleep outcomes are reported, but beyond the scope of this article. For example, physical activity other than work was reported by $39.3 \%$ of participants.

\section{Prevalence of Sleepiness and Poor Sleep Hygiene}

As seen in Table 2, excessive sleepiness, as detected by the ESS was found in $47.4 \%$ of our participants ( $26 \%$ were classified as mildly sleepy, $9.4 \%$ as moderate, and $12 \%$ as seriously sleepy). Maladaptive sleep hygiene, as measured by the SHI, was prevalent among $85.7 \%$ of residents.

\section{Prevalence of Poor Sleep Quality}

Table 3 shows the self-rating by the respondents to the question 'What is the quality of your sleep?' with eight options ranging from extremely good to extremely poor. Results were $45.6 \%$ responded extremely good to good, $43.8 \%$ fair or adequate, $10.5 \%$ responded poor to extremely poor. In those with EDS, $36.7 \%$ rated quality as extremely good to good and $48.2 \%$ rated as fair or adequate and $15.1 \%$ responded poor to extremely poor.

\section{Prevalence of Subjective Sleepiness and Tiredness}

Participants were asked to indicate on a $0-10$ scale both how sleepy and how tired they were on the test day, with lower scores indicating less of these states. The mean score for self-rated responses to sleepiness was $4.41(S D=2.33)$ and tiredness $4.73(S D=2.62)$.

Table 4 shows the responses to Epworth Sleepiness Scale items, where the proportion of responses to moderate- to 


\section{TABLE 3}

Self Rated Sleep Quality on 1-8 Ordinal Scale by the Study Participants ${ }^{\star}$

\begin{tabular}{lccccc}
\hline & Frequency & Percent & Percent & NO EDS & EDS \\
\hline Extremely Good & 33 & 9.4 & 45.6 & $98(53.6)$ & $61(36.7)$ \\
Very Good & 53 & 15.1 & & & \\
Good & 74 & 21.1 & & & \\
\hline Adequate & 66 & 18.9 & 43.8 & $73(39.9)$ & $80(48.2)$ \\
Fair & 87 & 24.9 & & & \\
\hline Poor & 32 & 9.1 & 10.5 & $12(6.6)$ & $25(15.1)$ \\
Very Poor & 4 & 1.1 & & & \\
Extremely Poor & 1 & 0.3 & & & \\
\hline Total & 350 & 100 & 100 & $183(52.4)$ & $166(47.6)$ \\
\hline
\end{tabular}

Prevalence of Subjective Sleepiness and Tiredness

high chance of dozing was higher with items, 'Sitting \& Reading', Lying down to rest in the afternoon when circumstances permit', and 'Sitting quietly after lunch without alcohol'.

\section{TABLE 4}

Item Wise Responses to Epworth Sleepiness Scale by Study Participants

\begin{tabular}{|c|c|c|c|c|}
\hline \multirow{3}{*}{ Situation: } & \multicolumn{4}{|c|}{$\begin{array}{c}\text { Number of Participants Reporting Each Level of } \\
\text { Chance of dozing (\%): }\end{array}$} \\
\hline & 0 & 1 & 2 & 3 \\
\hline & $\begin{array}{c}\text { would never } \\
\text { doze }\end{array}$ & $\begin{array}{l}\text { slight chance } \\
\text { of dozing }\end{array}$ & $\begin{array}{c}\text { moderate } \\
\text { chance of } \\
\text { dozing }\end{array}$ & $\begin{array}{c}\text { high chance } \\
\text { of dozing }\end{array}$ \\
\hline $\begin{array}{l}\text { Sitting \& } \\
\quad \text { Reading }\end{array}$ & $48(13.8)$ & $134(38.5)$ & $110(31.6)$ & $56(16.1)$ \\
\hline Watching TV & $125(36.1)$ & $134(38.4)$ & $58(16.6)$ & 31 (8.9) \\
\hline $\begin{array}{l}\text { Sitting inactive } \\
\text { in a public } \\
\text { place (e.g. a } \\
\text { theater or } \\
\text { movie) }\end{array}$ & $145(41.5)$ & $116(33.2)$ & $56(16.6)$ & $32(9.2)$ \\
\hline $\begin{array}{l}\text { As a passenger } \\
\text { in a car for an } \\
\text { hour without } \\
\text { a break }\end{array}$ & $71(20.4)$ & $107(30.7)$ & $99(28.4)$ & $171(20.4)$ \\
\hline $\begin{array}{l}\text { Lying down to } \\
\text { rest in the } \\
\text { afternoon } \\
\text { when circum- } \\
\text { stances } \\
\text { permit }\end{array}$ & $14(4)$ & $50(14.4)$ & $112(32.3)$ & $171(49.3)$ \\
\hline $\begin{array}{l}\text { Sitting \& talking } \\
\text { with } \\
\text { Someone }\end{array}$ & $263(75.6)$ & $73(21)$ & $10(2.9)$ & $2(0.6)$ \\
\hline $\begin{array}{l}\text { Sitting quietly } \\
\text { after lunch } \\
\text { without } \\
\text { alcohol }\end{array}$ & 40 (11.5) & $125(35.8)$ & $121(34.7)$ & $63(18.1)$ \\
\hline $\begin{array}{l}\text { In a car, while } \\
\text { stopped for a } \\
\text { few minutes } \\
\text { in traffic }\end{array}$ & $245(70.4)$ & $84(24.1)$ & $14(4)$ & $5(1.4)$ \\
\hline
\end{tabular}

TABLE 5

Sleep Hygiene Index (SHI) Mean Scores in Participants With and Without EDS

\begin{tabular}{lcccccc}
\hline & \multicolumn{7}{c}{ SHI score } \\
\cline { 2 - 7 } ESS & $\mathrm{N}$ & Mean & SD & SE & $t$ & $p$ \\
\hline No EDS & 183 & 30.92 & 6.18 & 0.46 & & \\
EDS & 166 & 33.48 & 5.61 & 0.44 & -4.026 & $<0.001$
\end{tabular}

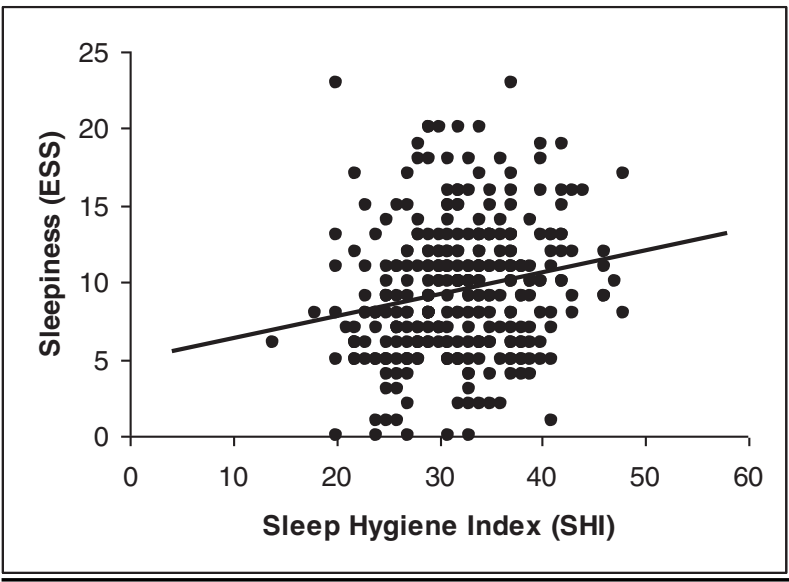

FIGURE 1

Linear regression curve of SHI scores with original ESS scores.

\section{Relationship of EDS to Poor Sleep Hygiene}

Table 5 shows comparisons of mean SHI scores in No EDS and EDS groups. The mean score for 183 respondents with No EDS was $30.92(S D=6.18)$ and for 166 respondents with EDS $33.48(S D=5.61)$. The difference in means was statistically significant.

Figure 1 shows the small but significant positive relationship between sleepiness and sleep hygiene $(r(348)=0.186$; $p<.001)$.

Table 6 shows the odds ratio for association between sleep hygiene and excessive daytime sleepiness. The MantelHaenszel (Nichols, 1994) common odds ratio was estimated to be 2.98, with Breslow-Day and Tarone tests of homogeneity of odds ratio and Mantel-Haenszel test for conditional independence being significant $(\mathrm{p}<0.001)$. The MantelHaenszel chi-square is 10.85 with a $p$ value of .000988 . The role of chance for odds ratio was ruled out with $\mathrm{p}<.001$.

TABLE 6

Association of Sleep Hygiene with EDS

\begin{tabular}{|c|c|c|c|c|c|c|}
\hline & & \multicolumn{2}{|c|}{ ESS scale } & \multirow[b]{2}{*}{ OR } & \multirow[b]{2}{*}{$p$} & \multirow{2}{*}{$\begin{array}{c}95 \% \mathrm{Cl} \text { for } \\
\text { OR } \\
\text { ( } p \text { for OR) }\end{array}$} \\
\hline & & No EDS & EDS & & & \\
\hline \multirow[t]{2}{*}{ SHI scale } & $\begin{array}{l}\text { More } \\
\text { Adaptive }\end{array}$ & $37(74 \%)$ & $13(26 \%)$ & 2.98 & 0.001 & $\begin{array}{c}1.54-5.83 \\
(0.001)\end{array}$ \\
\hline & $\begin{array}{l}\text { Less } \\
\qquad \text { Adaptive }\end{array}$ & $146(51.2 \%)$ & $153(48.8 \%)$ & & & \\
\hline
\end{tabular}




\section{TABLE 7}

Item Wise ratings of SHI by Study Participants

\begin{tabular}{|c|c|c|c|c|c|c|}
\hline \multicolumn{7}{|c|}{ Sleep Hygiene Index } \\
\hline \multicolumn{7}{|c|}{$\begin{array}{l}\text { Please rate all of the following statements using the scale below. } \\
5=\text { Always }\end{array}$} \\
\hline \multicolumn{7}{|c|}{$4=$ Frequently } \\
\hline \multicolumn{7}{|c|}{$3=$ Sometimes } \\
\hline \multicolumn{7}{|c|}{$2=$ Rarely } \\
\hline \multicolumn{7}{|c|}{$1=$ Never } \\
\hline \multirow{2}{*}{\multicolumn{2}{|c|}{$\begin{array}{l}\text { Sleep Hygiene Index } \\
\text { Please circle the letters or blacken the box by using the scale } \\
\text { above. }\end{array}$}} & $\mathrm{N}=(\%)$ & $\mathrm{N}=(\%)$ & $\mathrm{N}=(\%)$ & $\mathrm{N}=(\%)$ & $\mathrm{N}=(\%)$ \\
\hline & & & & & & \\
\hline 1. & I take daytime naps lasting two or more hours. & $103(29.5)$ & $142(40.7)$ & $80(22.9)$ & $16(4.6)$ & $8(2.3)$ \\
\hline 2. & I go to bed at different times from day to day. & $23(6.6)$ & $74(21.3)$ & $89(25.6)$ & $100(28.7)$ & $62(17.8)$ \\
\hline 3. & I get out of bed at different times from day to day. & $40(11.5)$ & 101 (28.9) & $103(29.5)$ & 73 (20.9) & $32(9.2)$ \\
\hline 4. & $\begin{array}{l}\text { I exercise to the point of sweating within one hour of going } \\
\text { to bed. }\end{array}$ & $274(78.7)$ & $50(14.4)$ & $17(4.9)$ & $1(0.3)$ & $6(1.7)$ \\
\hline 5. & I stay in bed longer than I should two or three times a week. & $96(27.5)$ & $110(31.5)$ & $85(24.4)$ & $41(11.7)$ & $17(4.9)$ \\
\hline 6. & $\begin{array}{l}\text { I use alcohol, tobacco, or caffeine within four hours of going } \\
\text { to bed or after going to bed. }\end{array}$ & $224(64.2)$ & 45 (12.9) & $49(14)$ & $19(5.4)$ & $12(3.4)$ \\
\hline 7. & $\begin{array}{l}\text { I do something that may wake me up before bedtime } \\
\text { (for example: play video games, use the internet, or clean). }\end{array}$ & $142(40.7)$ & $70(20.1)$ & $94(26.9)$ & $33(9.5)$ & $10(2.9)$ \\
\hline 8. & I go to bed feeling stressed, angry, upset, or nervous. & $71(20.3)$ & $100(28.7)$ & $113(32.4)$ & $57(16.3)$ & $8(2.3)$ \\
\hline 9. & $\begin{array}{l}\text { I use my bed for things otherthan sleeping or sex (for example: } \\
\text { watch television, read, eat, or study). }\end{array}$ & $37(10.6)$ & $45(12.9)$ & $88(25.2)$ & $111(31.8)$ & $68(19.5)$ \\
\hline 10. & $\begin{array}{l}\text { I sleep on an uncomfortable bed (for example: poor mattress } \\
\text { or pillow, too much or not enough blankets). }\end{array}$ & $126(36.2)$ & $109(31.3)$ & $68(19.5)$ & $28(8)$ & $17(4.9)$ \\
\hline 11. & $\begin{array}{l}\text { I sleep in an uncomfortable bedoom (for example: too } \\
\text { bright, too stuffy, too hot, too cold, or too noisy). }\end{array}$ & $105(30.1)$ & $128(36.7)$ & 65 (18.6) & $34(9.7)$ & $17(4.9)$ \\
\hline 12. & $\begin{array}{l}\text { I do important work before bedtime (for example: pay } \\
\text { bills, schedule, or study). }\end{array}$ & $32(9.2)$ & $56(16)$ & $95(27.2)$ & $127(36.4)$ & $39(11.2)$ \\
\hline 13. & I think, plan, or worry when I am in bed. & $43(12.3)$ & $84(24.1)$ & $127(36.4)$ & $68(19.5)$ & $27(7.7)$ \\
\hline
\end{tabular}

The $95 \%$ confidence interval ranged from lower bound limit 1.54 and upper bound limit 5.83 .

Table 7 shows that actual ratings of SHI items by resident doctors as having performed these behaviours always to never on an ordered scale. Items $2,3,9,12$, and 13 have been reported as frequently to always by relatively more number of resident doctors.

Table 8 shows the mean differences and statistical difference in the means between EDS and No EDS groups. The EDS group was significantly more likely than the No EDS group to have variable bedtimes $(t(346)=-3.38 ; p<.05)$, to have variable wake times $(t(347)=-2.63 ; p<.05)$, to stay in bed longer than they should two to three times per week $(t(347)=-2.16 ; p<.05)$, to go to bed feeling stressed, angry, upset or nervous; to use their bed for things other than sleeping or sex $(t(347)=-3.85 ; p<.05)$; and to think, plan, or worry in bed to have variable bedtimes $(t(347)=$ $-1.83 ; p<.05)$.

\section{Relationship of EDS to Sleep Duration and Work Time}

Prevalence odds ratios show that there is a 1.7 times greater chance of developing EDS when working $>80$ hours (Table 9), suggesting that limiting work hours to 80 hour per week is associated with lower levels of EDS.

Table 10 shows the self-reported mean hours of sleep duration in the recent past in resident doctors with and without EDS on Epworth Sleepiness Scale (ESS). Compared to the EDS group, the No EDS group obtained significantly more sleep in an average week, spent significantly more time in bed on an average night and took significantly less time to fall asleep. 


\section{TABLE 8}

Sleep Hygiene Index (SHI) Item Means in Study Subjects With and Without EDS

\begin{tabular}{|c|c|c|c|c|}
\hline $\mathrm{SHI} \#$ & Sleep Hygiene Index parameter & $\begin{array}{c}\text { No EDS } \\
\text { Mean(SD) } \\
(\mathrm{N}=183)\end{array}$ & $\begin{array}{c}\text { EDS } \\
\text { Mean(SD) } \\
(N=166)\end{array}$ & $p$ \\
\hline 1 & $\begin{array}{l}\text { I take daytime naps lasting two } \\
\text { or more hours }\end{array}$ & $2.07(0.89)$ & $2.13(1.02)$ & 0.276 \\
\hline 2 & $\begin{array}{l}\text { I go to bed at different times } \\
\text { from day to day }\end{array}$ & $3.10(1.18)$ & $3.52(1.14)$ & 0.001 \\
\hline 3 & $\begin{array}{l}\text { I get out of bed at different } \\
\text { times from day to day }\end{array}$ & $2.72(1.15)$ & $3.04(1.12)$ & 0.005 \\
\hline 4 & $\begin{array}{l}\text { I exercise to the point of } \\
\text { sweating within one hour of } \\
\text { going to bed }\end{array}$ & $1.32(0.75)$ & $1.32(0.72)$ & 0.479 \\
\hline 5 & $\begin{array}{l}\text { I stay in bed longer than I } \\
\text { should two or three times a } \\
\text { week }\end{array}$ & $2.22(1.06)$ & $2.49(1.21)$ & 0.02 \\
\hline 6 & $\begin{array}{l}\text { I use alcohol, tobacco, or } \\
\text { caffeine within four hours of } \\
\text { going to bed or after going } \\
\text { to bed }\end{array}$ & $1.67(1.08)$ & $1.75(1.15)$ & 0.249 \\
\hline 7 & $\begin{array}{l}\text { I do something that may wake } \\
\text { me up before bedtime (for } \\
\text { example: play video games, } \\
\text { use the internet, or clean) }\end{array}$ & $2.04(1.09)$ & $2.24(1.19)$ & 0.063 \\
\hline 8 & $\begin{array}{l}\text { I go to bed feeling stressed, } \\
\text { angry, upset, or nervous }\end{array}$ & $2.31(1.04)$ & $2.74(1.04)$ & $<0.000$ \\
\hline 9 & $\begin{array}{l}\text { I use my bed for things other } \\
\text { than sleeping or sex (for } \\
\text { example: watch television, } \\
\text { read, eat, or study) }\end{array}$ & $3.26(1.24)$ & $3.49(1.21)$ & 0.040 \\
\hline 10 & $\begin{array}{l}\text { I sleep on an uncomfortable } \\
\text { bed (for example: poor } \\
\text { mattress or pillow, too much } \\
\text { or not enough blankets) }\end{array}$ & $2.05(1.09)$ & $2.24(1.19)$ & 0.059 \\
\hline 11 & $\begin{array}{l}\text { I sleep in an uncomfortable } \\
\text { bedroom (for example: too } \\
\text { bright, too stuffy, too hot, } \\
\text { too cold, or too noisy) }\end{array}$ & $2.19(1.13)$ & $2.27(1.12)$ & 0.240 \\
\hline 12 & $\begin{array}{l}\text { I do important work before } \\
\text { bedtime (for example: pay } \\
\text { bills, schedule, or study) }\end{array}$ & $3.23(1.18)$ & $3.25(1.08)$ & 0.441 \\
\hline 13 & $\begin{array}{l}\text { I think, plan, or worry when I } \\
\text { am in bed }\end{array}$ & $2.76(1.10)$ & $2.98(1.10)$ & 0.034 \\
\hline
\end{tabular}

These participants showed a significant relationship between weekly work hours, sleep hygiene and EDS. Table 11 shows that, for participants working 80 hours per week or less, good sleep hygiene is associated with low probability of EDS; but that even with low work hours poor sleep hygiene showed a significant increase in EDS. For participants

\section{TABLE 9}

Association of Duration of Weekly Work Hours With EDS

\begin{tabular}{|c|c|c|c|c|c|c|}
\hline & & $\begin{array}{l}\text { EDS } \\
\mathrm{N}(\%)\end{array}$ & $\begin{array}{c}\text { No EDS } \\
N(\%)\end{array}$ & $\begin{array}{c}\chi^{2} \\
\text { test } p\end{array}$ & OR & $\begin{array}{c}95 \% \mathrm{Cl} \\
\text { OR }(p)\end{array}$ \\
\hline \multirow[t]{2}{*}{$\begin{array}{l}\text { Work hours } \\
\text { in } 1 \text { week }\end{array}$} & $>80$ hours & $\begin{array}{c}105 \\
(53.3)\end{array}$ & $\begin{array}{c}92 \\
(46.7)\end{array}$ & 0.015 & 1.70 & $\begin{array}{r}1.10-2.61 \\
(0.015)\end{array}$ \\
\hline & $\begin{array}{c}80 \text { hours } \\
\text { or less }\end{array}$ & $\begin{array}{c}61 \\
(40.1)\end{array}$ & $\begin{array}{c}91 \\
(59.9)\end{array}$ & & & \\
\hline
\end{tabular}

TABLE 10

Comparison of Means of Self Reported Sleep Characteristics Between EDS and No EDS Groups

\begin{tabular}{|c|c|c|c|c|}
\hline Sleep Characteristic & $\begin{array}{c}\text { EDS } \\
\text { Mean(SD) } \\
(\mathrm{N}=166)\end{array}$ & $\begin{array}{c}\text { No EDS } \\
\text { Mean(SD) } \\
(\mathrm{N}=183)\end{array}$ & $t$ & $p$ \\
\hline $\begin{array}{l}\text { Sleep duration in last } \\
1 \text { day }\end{array}$ & $6.05(1.36)$ & $6.34(1.41)$ & 1.921 & 0.196 \\
\hline $\begin{array}{l}\text { Sleep hours in last } \\
1 \text { week }\end{array}$ & $44.47(10.47)$ & $47.72(12.69)$ & 2.590 & 0.005 \\
\hline $\begin{array}{l}\text { Usual number of hours } \\
\text { spent sleeping per } \\
\text { night }\end{array}$ & $5.88(1.10)$ & $6.08(1.15)$ & 1.647 & 0.355 \\
\hline $\begin{array}{l}\text { Usual number of hours } \\
\text { spent on bed per night }\end{array}$ & $6.33(0.98)$ & $6.60(1.28)$ & 2.223 & 0.015 \\
\hline Sleep latency in minutes & $12.77(10.66)$ & $17.78(17.40)$ & 3.203 & 0.001 \\
\hline $\begin{array}{l}\text { Sleep Hygiene Index } \\
\text { (SHI) score }\end{array}$ & $33.48(5.61)$ & $30.92(6.18)$ & -4.026 & $<0.001$ \\
\hline
\end{tabular}

working more than 80 hours per week, sleep hygiene was not statistically associated with EDS.

\section{Discussion}

The sociodemographic profile of the resident physicians (see Table 1) revealed no differences in the prevalence of EDS due to sex, marital status, coffee intake or tobacco use. The present study revealed that $47.4 \%$ of the resident physicians studied were excessively sleepy (see Table 2 ). There have been no previous studies to assess country-level or specific work group prevalence of EDS in India. The results are comparable with the previous studies conducted with resident physicians in US and Europe (Handel, Raja, \& Lindsell, 2006; Papp et al., 2004; Rosen et al., 2004). A similar high prevalence of EDS had also been recorded in and outside of the US in other professions that are similar in respect to long work hours (Gallup Organization, 2003; Joo et al., 2005; Mello et al., 2000; Tsuno et al., 2007).

A little more than half of the physicians rated their sleep quality as fair to extremely poor (see Table 3). Of those doctors with EDS, nearly two thirds reported fair to extremely

\section{TABLE 11}

Stratified Analysis for Association Between EDS and Weekly Work Hours

\begin{tabular}{llcccc}
\hline \multicolumn{2}{c}{ Weekly work hours } & No EDS & EDS & $\chi^{2}$ test $p$ & $\begin{array}{r}\text { Adjusted } \\
(\mathrm{MH}) \mathrm{OR}^{*}\end{array}$ \\
\hline 80 or less & Hygienic & $20(95.2 \%)$ & $1(4.8 \%)$ & $<.001$ & 3.161 \\
per week & Un Hygienic & $71(54.2 \%)$ & $60(45.8 \%)$ & & $\begin{array}{c}(95 \% \mathrm{Cl} \\
1.5-6.3)\end{array}$ \\
& & & & \\
$\begin{array}{l}\text { More than } \\
\begin{array}{l}80 \text { per } \\
\text { week }\end{array}\end{array}$ & Ung Hygienic & $17(58.6 \%)$ & $12(41.4 \%)$ & 0.164 & \\
\hline${ }^{*} \mathrm{MH}-$ Mantel-Haenszel Odds Ratio & $75(44.6 \%)$ & $93(55.4 \%)$ & & \\
\end{tabular}


poor sleep quality. It is generally accepted that poor sleep quality is an important precursor of EDS (Hasler et al., 2005; LeBourgeois, Avis, Mixon, Olmi, \& Harsh, 2004; Vignatelli et al., 2006). It appears that the residents with EDS had some awareness of their own sleep difficulties. However, scores from a visual analogue scale self-rating 0-10 for 'How sleepy are you today?' and 'How tired are you today?', although statistically higher for the EDS group, were not generally high for either group. It may be that the studied physicians had some awareness of sleep quality problems, but either were unwilling to admit or were unaware of the presence of their own excessive daytime sleepiness.

An examination of the Epworth Sleepiness Scale scores, where respondents were asked to self-report their own chances of falling asleep under various environmental conditions (see Table 4), revealed that almost $25 \%$ of the studied physicians reported a slight or greater chance of falling asleep while sitting and talking to someone and over $25 \%$ admitted they had a slight or greater chance of falling asleep while stopped in traffic. In summary, it appears that although many subjects described poor sleep quality and the potential to fall asleep, most rated their current levels of tiredness and sleepiness as moderate. If these physicians are unable and/or unwilling to identify current levels of tiredness or sleepiness, it becomes more important to understand why these states exist and what interventions could be suggested.

The mean sleep hygiene scores were higher (i.e., more maladaptive) for the sleepy physicians (see Table 5) and a positive correlation was found between sleepiness and sleep hygiene (see Figure 1). The prevalence of EDS in the group with more maladaptive sleep hygiene was $48.8 \%$, whereas the prevalence of EDS in the more adaptive sleep hygiene group was $26 \%$. Another means of communicating this relationship is that physicians with more maladaptive sleep behaviours as indicated by SHI had a three times higher chance of experiencing EDS (see Table 6). As the Sleep Hygiene Index is constructed by a set of potentially independent items, it is as important to consider the items individually.

Five SHI items (see Table 7) were identified (2, 3, 9, 12 and 13) as having been engaged in as frequently to always by relatively more physicians. Of the overall total SHI scores, $44.32 \%$ was contributed by the frequently to always categories of these items. Items two and three ('I go to bed and get out of bed at different times') pertain to maintaining a regular time for going to and rising from bed. We suggest these maladaptive behaviours are likely a result of unstable work schedules. Item nine and thirteen ('I use my bed for things other than sleeping or sex' and 'I think, plan, or worry when I am in bed') are likely related to limited space available in hostel rooms where many of these residents reside. Most medical residents in India are assigned a single ten by ten foot room with a study table, a chair and a cot. This may have led the subjects to use their bed for nonsleep purposes such as work, study or other activating behaviours. Finally, item 12 ('I do important work before bedtime') may reflect their effort to manage time when working extended work schedules.

Six SHI items (see Table 8) were identified (2, 3, 5, 8, 9 and 13) as having been engaged in more frequently by physicians with EDS. Of the overall total SHI scores, 53.6\% was contributed by these items. Items 2 and 3 ('I go to bed and get out of bed at different times') and item 9 ('I use my bed for things other than sleeping or sex') were again identified as problematic. Additionally, item 5 ('I stay in bed longer than I should two or three times a week') is likely a result of attempted extended recovery sleep. Items 8 ('I go to bed feeling stressed, angry, upset, or nervous') and 13 ('I think, plan, or worry when I am in bed') suggest emotional disruption in combination with a sleep debt resulting in stimulus discrimination problems.

Among the residents with EDS, $36.7 \%$ were working 80 or fewer hours per week and $63.3 \%$ were working more than 80 hours per week. The frequencies (see Table 9) were significantly different and suggest a 1.7 times greater risk of EDS for those subjects working more than 80 hours per week. An association between higher work hours in a week and EDS has been demonstrated in several studies from a number of different countries, including Canada (Hanlon et al., 2009), New Zealand (Gander et al., 2007), United States (Defoe et al., 2001; Gander et al. 2007), Australia (Dorrian et al., 2006), Japan (Kaneita et al., 2005) and others (Groeger, Zijlstra, \& Dijk, 2004; Jagsi et al., 2008; Jewett, Dijk, Kronauer, \& Dinges, 1999; Kaneita et al., 2005; Klerman \& Dijk, 2005; Liu, Uchiyama, Kim, et al., 2000; Ohida et al., 2004; Skeff, Ezeji-Okoye, Pompei, \& Rockson, 2004; Steinbrook, 2002).

The self-reported total hours slept in one week by resident doctors differed significantly between the EDS and No EDS groups (6.05 vs. 6.34; see Table 10). The effect of inadequate sleep on EDS is well documented in resident physicians and the general population, (Dorrian et al., 2006; Groeger et al., 2004; Jewett et al., 1999; Kaneita et al., 2005; Klerman \& Dijk, 2005; Liu, Uchiyama, Kim, et al., 2000; Liu, Uchiyama, Okawa, et al., 2000; Ohida et al., 2004; Takegami, Sokejima, Yamazaki, Nakayama, \& Fukuhara, 2005), but this is the first study of its kind available from India (Gupta, Pati, \& Levi, 1997; Kannan, Malhotra, Bajaj, Pershad, \& Chari, 1996). Suggested explanations for an association between sleepiness and work hours includes stress related to work, burnout, inadequate sleep hours, sleep deprivation and sleep debt and other work-related characteristics like floating shift work.

The overall mean work hours per week in our study exceeded the weekly work hour norms established by medical education regulation boards in some countries (Accreditation Council for Graduate Medical Education, 2007; Accreditation Council on Graduate Medical Education, 2002; Resident Duty Hours: Enhancing Sleep, Supervision, and Safety, 2008). For example, in 2003 in the US, the Accreditation Council for Graduate Medical Education set up legally binding guidelines limiting the work hours to 80 per week and 
not more than 24 consecutively (Accreditation Council on Graduate Medical Education). Such regulations also exist in Australia (Gander et al., 2007), Canada, the United Kingdom (Cappuccio et al., 2009) and other European countries. Recent recommendations from the Institute of Medicine in the US have reaffirmed the need for stricter adherence (Resident Duty Hours: Enhancing Sleep, Supervision, and Safety, 2008). Even though the problem of unregulated long hours and their consequences exist, there are no policy documents available limiting the work hours of trainee doctors or medical professionals in India. At the particular institution studied here (Postgraduate Institute of Medical Education and Research), there were no set guidelines on resident work hours and working conditions.

It appears that for these resident doctors, hours worked interacted with hours slept and a maladaptive sleep lifestyle leading to EDS (see Table 11). In the group working 80 or less hours a week, the prevalence of EDS differed significantly between the adaptive and maladaptive sleep hygiene groups ( $4.8 \%$ vs. $45.8 \%$ respectively; see Table 11 ). Whereas the prevalence of EDS in those with adaptive and maladaptive sleep hygiene for residents working 80 hours per week and more was not significantly different ( $41.4 \%$ vs. $54.4 \%$ respectively). It is likely that individuals working more than 80 hours a week are sleepy regardless of sleep hygiene practices.

We suggest that for these residents, sleep hygiene and work hours interact as risk factors to predict EDS. In residents with 80 or less hours of work, sleep hygiene plays an important role in anticipating EDS and when the work hours extend beyond 80 hours, sleep time and sleep hygiene may become curtailed/disrupted to the extent that avoiding sleepiness may be difficult.

\section{Limitations}

Of the 430 resident doctors in this study who were solicited to volunteer, 350 responded. The response rate was $81.77 \%$, better than similar studies on with attendees in India (65.3\%; Alattar, Harrington, Mitchell, \& Sloane, 2007), in junior doctors in New Zealand (63\%; Gander et al., 2007), and in Canadian anaesthesia residents (77\%; Hanlon et al., 2009).

This study was based on self-report. There were chances of biases such as socially desirable responses and the accuracy of reported information. In addition, some of the responses involved reporting of events up to one month prior such that recollection may have been an issue.

Even though the tools were validated in the context of western countries and some Asian nations, good quality studies validating the ESS and SHI from India were not available. Fluency in written English is a requirement for the subjects and was not considered an issue. The relevance of these instrument items in the Indian context for resident doctors is unknown. Some junior residents reported that they did not face some of the situations mentioned in the
ESS in the recent past. The effect of responses in such cases on results is unknown.

\section{Conclusion}

Almost half of the resident physicians studied reported a problem of EDS and maladaptive sleep hygiene practices. Sleep hygiene and number of hours slept should be considered as EDS prevention and treatment strategies, especially for physicians working less than 80 hours per week. Physicians working more than 80 hours per week were much more likely to report EDS. We suggest the most salient intervention for physicians working more than 80 hours per week is one of workplace advocacy where the government is encouraged to adopt legally binding guidelines as seen in other countries, such as limiting the work hours to 80 per week and not more than 24 hours consecutively.

\section{References}

Accreditation Council for Graduate Medical Education. (2007). Duty hours language. Retrieved from http://www. acgme.org/acWebsite/dutyHours/dh_Lang703.pdf

Accreditation Council on Graduate Medical Education. (2002). Report of the ACGME Work Group on Resident Duty Hours. Chicago: Accreditation Council on Graduate Medical Education.

Akerstedt, T. (2003). Shift work and disturbed sleep/wakefulness. Occupational Medicine (London), 53(2), 89-94.

Alattar, M., Harrington, J.J., Mitchell, C.M., \& Sloane, P. (2007). Sleep problems in primary care: A North Carolina Family Practice Research Network (NC-FP-RN) study. Journal of the American Board of Family Medicine, 20(4), 365-374. doi:20/4/365 [pii] 10.3122/jabfm.2007.04.060153

Azad, N., Byszewski, A., Sarazin, F.F., McLean, W., \& Koziarz, P. (2003). Hospitalized patients' preference in the treatment of insomnia: Pharmacological versus non-pharmacological. Canadian Journal of Clinical Pharmacology, 10(2), 89-92.

Bartel, P., Offermeier, W., Smith, F., \& Becker, P. (2004). Attention and working memory in resident anaesthetists after night duty: group and individual effects. Occupational and Environmental Medicine, 61(2), 167-170.

Brown, F.C., Buboltz, W.C., Jr., \& Soper, B. (2002). Relationship of sleep hygiene awareness, sleep hygiene practices, and sleep quality in university students. Behavioral Medicine, 28(1), 33-38.

Cappuccio, F.P., Bakewell, A., Taggart, F.M, Ward, G., Ji, C., Sullivan, J.P., Edmunds, M., Pounder, R., Landrigan, C.P., Lockley, S.W., \& Peile, E. (2009). Implementing a $48 \mathrm{~h}$ EWTD-compliant rota for junior doctors in the UK does not compromise patients' safety: Assessor-blind pilot comparison. Quarterly Journal of Medicine, 102(4), 271-282. doi:10.1093/qjmed/hcp004

Chesson, A.L., Jr., Anderson, W.M., Littner, M., Davila, D., Hartse, K., Johnson, S., Rafecas, J. (1999). Practice parameters for the nonpharmacologic treatment of chronic 
insomnia. An American Academy of Sleep Medicine report. Standards of Practice Committee of the American Academy of Sleep Medicine. Sleep, 22(8), 1128-1133.

Daley, M., Morin, C.M., LeBlanc, M., Gregoire, J.P., \& Savard, J. (2009). The economic burden of insomnia: Direct and indirect costs for individuals with insomnia syndrome, insomnia symptoms, and good sleepers. Sleep, 32(1), 5564.

Daley, M., Morin, C.M., LeBlanc, M., Gregoire, J.P., Savard, J., \& Baillargeon, L. (2009). Insomnia and its relationship to health-care utilization, work absenteeism, productivity and accidents. Journal of Sleep Medicine, 10(4), 427-438. doi:10.1016/j.sleep.2008.04.005

Defoe, D.M., Power, M.L., Holzman, G.B., Carpentieri, A., \& Schulkin, J. (2001). Long hours and little sleep: Work schedules of residents in obstetrics and gynecology. Obstetrics and Gynecology, 97(6), 1015-1018. doi:S0029-7844(01)013631 [pii]

Doi, Y., Minowa, M., \& Futija, T. (2002). Excessive daytime sleepiness and its associated factors among male non-shift white-collar workers. Journal of Occupational Health, 44, 145-150.

Dorrian, J., Lamond, N., van den Heuvel, C., Pincombe, J., Rogers, A.E., \& Dawson, D. (2006). A pilot study of the safety implications of Australian nurses' sleep and work hours. Chronobiology International, 23(6), 11491163. doi:10.1080/07420520601059615

Gaba, D.M., \& Howard, S.K. (2002). Patient safety: Fatigue among clinicians and the safety of patients. New England Journal of Medicine, 347(16), 1249-1255. doi:10.1056/NEJMsa020846

Gallup Organization. (2003). National survey of distracted and drowsy driving attitudes and behaviors: 2002. Washington, DC: National Highway Traffic Safety Administration.

Gander, P., Purnell, H., Garden, A., \& Woodward, A. (2007). Work patterns and fatigue-related risk among junior doctors. Occupational and Environmental Medicine, 64(11), 733-738. doi:10.1136/oem.2006.030916

Groeger, J.A., Zijlstra, F.R., \& Dijk, D.J. (2004). Sleep quantity, sleep difficulties and their perceived consequences in a representative sample of some 2000 British adults. Journal of Sleep Research, 13(4), 359-371. doi:10.1111/j.13652869.2004.00418.x

Gupta, S., Pati, A.K., \& Levi, F. (1997). Pattern of shift rota modulates oral temperature circadian rhythm and sleepwakefulness profiles in shift workers. Journal of Biosciences, 22(4), 477-488.

Handel, D.A., Raja, A., \& Lindsell, C.J. (2006). The use of sleep aids among Emergency Medicine residents: A web based survey. BioMed Health Central Health Services Research, 6, 136. doi:10.1186/1472-6963-6-136

Hanlon, J.G., Hayter, M.A., Bould, M.D., Joo, H.S., \& Naik, V.N. (2009). Perceived sleepiness in Canadian anesthesia residents: A national survey. Canadian Journal of Anaesthesiology, 56(1), 27-34. doi:10.1007/s12630-008-9003-8

Harsora, P., \& Kessmann, J. (2009). Nonpharmacologic management of chronic insomnia. American Family Physician, $79(2), 125-130$.
Hasler, G., Buysse, D.J., Gamma, A., Adjacic, V., Eich, D., Rossler, W., \& Angst, J. (2005, April). Excessive daytime somnolence in young adults: A 20-year prospective community study. Journal of Clinical Psychiatry, 66(4), 521529.

Hoch, C.C., Reynolds, C.F., 3rd, Buysse, D.J., Monk, T.H., Nowell, P., Begley, A.E., \& Dew, M.A. (2001). Protecting sleep quality in later life: A pilot study of bed restriction and sleep hygiene. Journals of Gerontologyy Series B: Psychological and Social Sciences, 56(1), P52-59.

Howard, S.K., Gaba, D.M., Rosekind, M.R., \& Zarcone, V.P. (2002). The risks and implications of excessive daytime sleepiness in resident physicians. Academic Medicine, 77(10), 1019-1025.

Institute of Medicine of the National Academies. (2008) Resident Duty Hours: Enhancing Sleep, Supervision, and Safety. Washington, DC: Committee on Optimizing Graduate Medical Trainee (Resident) Hours and Work Schedules.

Jagsi, R., Weinstein, D.F., Shapiro, J., Kitch, B.T., Dorer, D., \& Weissman, J.S. (2008). The Accreditation Council for Graduate Medical Education's limits on residents' work hours and patient safety. A study of resident experiences and perceptions before and after hours reductions. Archives of Internal Medicine, 168(5), 493-500. doi:10.1001/archinternmed.2007.129

Jennum, P., Knudsen, S., \& Kjellberg, J. (2009). The economic consequences of narcolepsy. Journal of Clinical Sleep Medicine, 5(3), 240-245.

Jewett, M.E., Dijk, D.J., Kronauer, R.E., \& Dinges, D.F. (1999). Dose-response relationship between sleep duration and human psychomotor vigilance and subjective alertness. Sleep, 22(2), 171-179.

Johns, M.W. (1991). A new method for measuring daytime sleepiness: The Epworth Sleepiness scale. Sleep, 14(6), 540545.

Johns, M.W. (1992). Reliability and factor analysis of the Epworth Sleepiness Scale. Sleep, 15(4), 376-381.

Joo, S., Shin, C., Kim, J., Yi, H., Ahn, Y., Park, M., \& Lee, S. (2005). Prevalence and correlates of excessive daytime sleepiness in high school students in Korea. Psychiatry and Clinical Neurosciences, 59(4), 433-440. doi:10.1111/j.14401819.2005.01396.x

Kaneita, Y., Ohida, T., Uchiyama, M., Takemura, S., Kawahara, K., Yokoyama, E., \& Akashiba, T. (2005). Excessive daytime sleepiness among the Japanese general population. Journal of Epidemiology, 15(1), 1-8.

Kannan, S., Malhotra, S. K., Bajaj, A., Pershad, D., \& Chari, P. (1996). Sleep deprivation in anaesthetists: Effect on short term memory. Journal of Anaesthesiology, 12(4), 267-269.

Kleinman, N.L., Brook, R.A., Doan, J.F., Melkonian, A.K., \& Baran, R.W. (2009). Health benefit costs and absenteeism due to insomnia from the employer's perspective: A retrospective, case-control, database study. Journal of Clinical Psychiatry, 70(8), 1098-1104. doi:10.4088/JCP.08m04264

Klerman, E.B., \& Dijk, D.J. (2005). Interindividual variation in sleep duration and its association with sleep debt in young adults. Sleep, 28(10), 1253-1259. 
Krueger, G.P. (1994). Fatigue, performance, and medical error. In M.S. Bogner (Ed.), Human Error in Medicine (pp. 311326). Hillsdale, NJ: L. Erlbaum Associates.

LeBourgeois, M.K., Avis, K., Mixon, M., Olmi, J., \& Harsh, J. (2004, May). Snoring, sleep quality, and sleepiness across attention-deficit/hyperactivity disorder subtypes. Sleep, 27(3), 520-525.

Leger, D. (1994). The cost of sleep-related accidents: A report for the National Commission on Sleep Disorders Research. Sleep, 17(1), 84-93.

Liu, X., Uchiyama, M., Kim, K., Okawa, M., Shibui, K., Kudo, Y., Doi, Y., Minowa, M., \& Ogihara, R. (2000). Sleep loss and daytime sleepiness in the general adult population of Japan. Psychiatry Research, 93(1), 1-11. doi:S01651781(99)00119-5 [pii]

Liu, X., Uchiyama, M., Okawa, M., \& Kurita, H. (2000). Prevalence and correlates of self-reported sleep problems among Chinese adolescents. Sleep, 23(1), 27-34.

Mastin, D.F., Bryson, J., \& Corwyn, R. (2006). Assessment of sleep hygiene using the Sleep Hygiene Index. Journal of Behavioral Medicine, 29(3), 223-227. doi:10.1007/s10865006-9047-6

Mello, M.T., Santana, M.G., Souza, L.M., Oliveira, P.C., Ventura, M.L., Stampi, C., \& Tufik, S. (2000). Sleep patterns and sleep-related complaints of Brazilian interstate bus drivers. Brazilian Journal of Medical and Biological Research, 33(1), 71-77. doi:S0100-879X(00)03300110 [pii]

Miletin, M.S., \& Hanly, P.J. (2003). Measurement properties of the Epworth sleepiness scale. Sleep Medicine, 4(3), 195-199. doi:S1389945703000315 [pii]

Mindell, J.A., Meltzer, L.J., Carskadon, M.A., \& Chervin, R.D. (2009). Developmental aspects of sleep hygiene: Findings from the 2004 National Sleep Foundation Sleep in America Poll. Sleep Medicine, 10(7), 771-779. doi:10.1016/j.sleep.2008.07.016

Nichols, D.P. (1994). The Mantel-Haenszel statistic for 2’2xK tables. SPSS Keywords, 54. Retrieved from ftp://ftp. software.ibm.com/software/analytics/spss/support/Stats/ Docs/Statistics/Articles/mh22k.htm

Ohayon, M.M., \& Lemoine, P. (2004). Daytime consequences of insomnia complaints in the French general population. Encephale, 30(3), 222-227. doi:MDOI-ENC-6-2004-30-30013-7006-101019-ART3 [pii]

Ohida, T., Osaki, Y., Doi, Y., Tanihata, T., Minowa, M., Suzuki, K., \& Kaneita, Y. (2004). An epidemiologic study of selfreported sleep problems among Japanese adolescents. Sleep, 27(5), 978-985.

Papp, K.K., Stoller, E.P., Sage, P., Aikens, J.E., Owens, J., Avidan, A., \& Strohl, K.P. (2004). The effects of sleep loss and fatigue on resident-physicians: A multi-institutional, mixed-method study. Academic Medicine, 79(5), 394-406.

Presser, M.B. (1999). Toward a 24-hour economy. Science, 284, 1178-1179.

Rosen, I.M., Bellini, L.M., \& Shea, J.A. (2004). Sleep behaviors and attitudes among internal medicine housestaff in a U.S. university-based residency program. Academic Medicine, 79(5), 407-416.
Roth, T., \& Roehrs, T. (2003). Insomnia: epidemiology, characteristics, and consequences. Clinical Cornerstone, 5(3), 5-15.

Roth, T., \& Roehrs, T.A. (1996). Etiologies and sequelae of excessive daytime sleepiness. Clinical Therapy, 18(4), 562576; discussion 561. doi:S0149-2918(96)80207-4 [pii]

Sandia National Laboratories, \& Sandia Corporation. (2007). Health Benefits employee Services. HBE preventive health sleep assessment form Retrieved April 2008, from http//hbe.sandia.gov

Saxena, A.D., \& George, C.F. (2005). Sleep and motor performance in on-call internal medicine residents. Sleep, 28(11), 1386-1391.

Siriwardena, A.N., Apekey, T., Tilling, M., Harrison, A., Dyas, J.V., Middleton, H.C., \& Qureshi, Z.M. (2009). Effectiveness and cost-effectiveness of an educational intervention for practice teams to deliver problem focused therapy for insomnia: Rationale and design of a pilot cluster randomised trial. BioMed Central Family Practice, 10, 9. doi:10.1186/1471-2296-10-9

Skeff, K.M., Ezeji-Okoye, S., Pompei, P., \& Rockson, S. (2004). Benefits of resident work hours regulation. Annals of Internal Medicine, 140(10), 816-817. doi:140/10/816 [pii]

Souza, J.C., Magna, L.A., \& Reimao, R. (2002). Excessive daytime sleepiness in Campo Grande general population, Brazil. Arquivos de Neuro-Psiquiatria, 60(3-A), 558-562. doi:S0004-282'2002000400008 [pii]

Steinbrook, R. (2002). The debate over residents' work hours. New England Journal of Medicine, 347(16), 1296-1302. doi:10.1056/NEJMhpr022383

Stepanski, E.J., \& Wyatt, J.K. (2003). Use of sleep hygiene in the treatment of insomnia. Sleep Medicine Review, 7(3), 215-225. doi:S1087079201902461

Suzuki, K., Ohida, T., Kaneita, Y., Yokoyama, E., \& Uchiyama, M. (2005). Daytime sleepiness, sleep habits and occupational accidents among hospital nurses. Journal of Advanced Nursing, 52, 445-453.

Takegami, M., Sokejima, S., Yamazaki, S., Nakayama, T., \& Fukuhara, S. (2005). [An estimation of the prevalence of excessive daytime sleepiness based on age and sex distribution of Epworth Sleepiness scale scores: A population based survey]. Nippon Koshu Eisei Zasshi, 52(2), 137145.

Tsuno, N., Jaussent, I., Dauvilliers, Y., Touchon, J., Ritchie, K., \& Besset, A. (2007). Determinants of excessive daytime sleepiness in a French community-dwelling elderly population. Journal of Sleep Research, 16(4), 364-371. doi:10.1111/j.1365-2869.2007.00606.x

Van Cauter, E., Holmback, U., Knutson, K., Leproult, R., Miller, A., Nedeltcheva, A., \& Spiegel, K. (2007). Impact of sleep and sleep loss on neuroendocrine and metabolic function. Hormone Research, 67(Suppl. 1), 2-9. doi:000097543 [pii] 10.1159/000097543

Vauth, C., \& Greiner, W. (2009). Aspects of health economics in the treatment of pain and sleep deficit. Deutsche Medizinische Wochenschrift, 134 (Suppl. 4), S144-147. doi:10.1055/s0029-1222592 
Veasey, S., Rosen, R., Barzansky, B., Rosen, I., \& Owens, J. (2002). Sleep loss and fatigue in residency training: a reappraisal. The Journal of the American Medical Association, 288(9), 1116-1124. doi:jrf10027 [pii]

Vignatelli, L., Bisulli, F., Naldi, I., Ferioli, S., Pittau, F., Provini, F., Plazzi, G., Vetrugno, R., Montagna, P., \& Tinuper, P. (2006). Excessive daytime sleepiness and subjective sleep quality in patients with nocturnal frontal lobe epilepsy: A case control study. Epilepsia, 47(Suppl. 5), 73-77.

Webb, W.B. (1995). The cost of sleep-related accidents: A reanalysis. Sleep, 18(4), 276-280.

Weiss, M.D., Wasdell, M.B., Bomben, M.M., Rea, K.J., \& Freeman, R.D. (2006). Sleep hygiene and melatonin treatment for children and adolescents with ADHD and ini- tial insomnia. Journal of the American Academy of Child and Adolescent Psychiatry, 45(5), 512-519. doi:10.1097/01 chi.0000205706.78818.ef

Wildschiodtz, G., \& Rasmussen, P.T. (1981). Sleep hygiene or hypnotics? Nordisk Medicine, 96(5), 152156.

Wols, M., Kramer, D., \& Strange, G.R. (1995). Resident service hours in emergency medicine. SAEM Education Committee. Academic Emergency Medicine, 2(2), 124127.

Zielinski, J., Polakowska, M., Kurjata, P., Kupsc, W., \& Zgierska, A. (1998). Excessive daytime somnolence in the adult population of Warsaw. Polskie Archiwum Medycyny Wewnetrznej, 99(5), 407-413. 